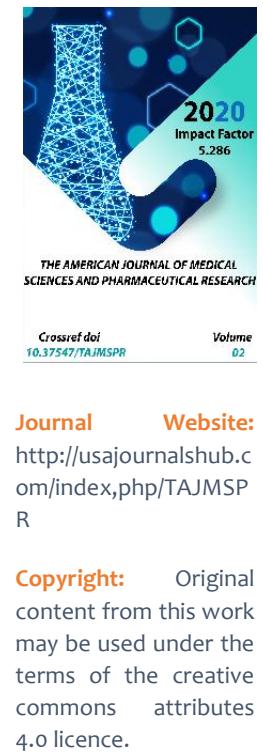

\title{
Immunogenetic Aspects Helicobacter Pylori Associated Gastroduodenal Pathology In Children
}

\author{
Shodieva Musharraf Sadirovna \\ Assistant of the Department Of Physiology Bukhara Statemedical Institute named Abu Ali Ibn \\ Sina, Uzbekistan.
}

\section{ABSTRACT}

We investigated the associations between the host HLA-DQ variation and the prevalence of $\mathrm{H}$ ruli in the Indonesian population with an $\mathrm{H}$. pylori-infected level of $11.2 \%$ in people living in the Bukhara region. It was noted that individuals carrying the $\mathrm{DQB}_{1}$ * 0401 genotypes are at significantly greater risk of developing $\mathrm{H}$ infection. .lori compared to individuals with the DQB1 0301 genotypes. The DQA1 or DQB1 haplotypes were not associated with $\mathrm{H}$. pulori infection.

\section{KEYWORDS}

Helicobacter pylori children, peptic ulcer, erosive gastroduodenitis, genotypes.

\section{INTRODUCTION}

Currently, chronic pathology of the stomach and duodenum in children and adolescents occupies a significant place in the structure of the overall morbidity [N. M. Zvyagina, O. V. Tetonov 2015]. The appeal of children to medical institutions for diseases of the digestive system does not reflect the true prevalence of this pathology. [Volkov A.I. 2012]. According to the results of the AllRussian dispensary examination, diseases of the digestive system rank second in the structure of childhood morbidity in adolescents. The incidence of chronic gastritis and chronic duodenitis in Russia is $300-400$ 
per 1000 child population [N. M. Zvyagina, O. V. Antonov 2015], and in the Tashkent region 200 per 1000 (Pazilova S.A. 2006). According to the forecasts of experts from the World Health Organization (WHO), by the middle of the XXI century, diseases of the digestive system will occupy one of the leading places, due to the lifestyle of a modern person (stress, poor nutrition, physical inactivity, bad habits), environmental pollution, an increase in the diet nutritional share of low-quality and genetically modified food products [Gurov A.N. 2015].

Helicobacter pylori ( $\mathrm{H}$. pylori) infection is currently considered as the leading etiopathogenetic factor of peptic ulcer disease (PUD) and chronic gastritis (CG) in childhood [Nizhevich A.A. et al. 2010]. The results of large-scale studies have shown that the share of peptic ulcer disease associated with infection with Helicobacter pylori accounts for $70-80 \%$ of cases of detection of duodenal ulcers and $50-60 \%$ of gastric ulcers [Suerbaum S., 2002]. There is more and more evidence of the role played by Helicobacter pylori infection in the occurrence and development of stomach cancer [Malekzadeh R., 2004; Hansen S. 2007; Yankin A.B., 2010]. Researchers associate $100 \%$ of cases of detection of proximal gastric cancer in Japanese with Helicobacter pylori infection [Uedo N .. 2003].

Tumor necrosis factor alpha (TNF- $\alpha$ ) is a proinflammatory cytokine synthesized mainly by macrophages and monocytes, which plays an important role in the initiation and enhancement of the immune-inflammatory response to infection with $\mathrm{H}$. pylori [GarciaGonzalez M.A. et al., 2005]. At the cellular level, TNF-a stimulates the production of proinflammatory cytokines such as interleukin-1, $6,-8$. Responsible for the immune and inflammatory response, including necrosis [Lee S.-G. et al., 2004]. The genes encoding them are among the main candidate genes of YB. Polymorphic variants of genes of cytokines and their receptors can have a significant impact on the risk of developing gastric ulcer and DU. In addition, the bacterium, inducing an immune-inflammatory response, contributes to the death of its own cells of the macroorganism, which causes the development of deep dystrophic and atrophic changes in the gastric mucosa with the phenomena of metaplasia and dysplasia. Further hyperplastic processes lead to the development of stomach cancer [S.A. Ankudinova 2008, M.A Adamu 2011, Correa P.2004, R.S. Konturek 2009, J. Watari 2014]. In this regard, early detection, timely diagnosis and treatment of children with precancerous conditions and changes in the gastric mucosa are relevant.

To study polymorphic variants of cytokine genes and their receptors in children with Helicobacter pylori associated gastroduodenal pathology.

\section{MATERIAL AND METHODS}

Peptic ulcer disease (PU) in childhood is no longer considered a rare disease and represents a serious problem in clinical medicine due to its high prevalence. Rejuvenation of pathology, chronic recurrent course, the possibility of life-threatening complications and a decrease in the effectiveness of treatment [1-3]. Despite the introduction of modern therapy regimens, over the past decade, the incidence of ulcer in schoolchildren has increased 2.5 times, the percentage of unsatisfactory results of inpatient treatment of patients has doubled, and the frequency of relapses has increased from 50 to $75 \%$. The complication rate increased 2.3 times [4; five]. Peptic ulcer 
disease and chronic erosive gastroduodenum (CEGD) are considered full-ethnic. Multifactorial diseases. The ethnological structure of $\mathrm{YaB}$ assumes three groups of reasons:

1)hereditary constitutional factors are numerous genetic markers of PUD: the most important of them are belonging to the 0 (I) blood group, non-secretory status, lack of fucoglycoproteids in gastric mucus, high levels of pepsinogen $I$ in the blood, 6-cell hyperplasia, detection of antigens of the HLA system : 2) exogenous factors - background symptoms. accompanying the child's life. neuro-emotional stress, violation of the regime of the day and rest, long-term alimentary inaccuracies, lack of nutrition of trace elements, vitamins, protein, long-term intake of certain medications, decrease in the body's resistance after diseases: 3) endogenous factors neuro-reflex effects on the stomach and duodenum (duodenum ) from other affected organs of the gastrointestinal tract, as well as the cardiovascular, endocrine systems; helicobacter pylori (HP) is considered one of the most important endogenous (infectious) factors [6: 7].

Currently, chronic pathology of the stomach and duodenum in children and adolescents occupies a significant place in the structure of overall morbidity [N. N1. Zvyagin. OV Antonov 2015 The turnover of children to medical institutions for diseases of the digestive system does not reflect the true prevalence of this pathology. [nine]. According to the results of the All-Russian dispensary examination, diseases of the digestive system rank second in the structure of childhood morbidity in adolescents. The incidence of chronic gastritis and chronic duodenitis in Russia is $300-400$ per 1000 child population [14]. and in the
Tashkent region 200 per 1000 (10). According to the forecasts of experts from the World Health Organization (WHO), by the middle of the 21st century, diseases of the digestive system will occupy one of the leading places, due to the lifestyle of a modern person (stress, poor nutrition, physical inactivity, bad habits). environmental pollution, an increase in the proportion of low-quality and genetically modified food in the diet [13].

Helicobacter pylori (HP) infection is currently considered as the leading etiopathogenetic factor of peptic ulcer disease (PUD) and chronic gastritis (CG) in childhood. Studies carried out in Russia and Europe have shown that the HLA system plays a fundamental role in the formation of the clinical variant of $\mathrm{N}$. pyor-associated gastroduodenal pathology and the clinical outcome of the disease (gastritis, gastroduodenal ulcer, ulcer, cancer, maltoma) [11].

The HLA genetic system is the most polymorphic human genetic system, which is explained by the biological role that HLA antigens play in maintaining the body's immunological homeostasis and protecting it from pathogens. The HLA gene complex is located on the short arm of chromosome 6 and includes a number of loci (A. B. C. DR. DQ. $D P)$. The product of the HLA A. B. C loci is called class I antigens, and the HLA DR loci. DQ and DP - class II antigens.

\section{RESULT AND DISCUSSION}

The polymorphism of the HLA system is responsible for variations in the body's immune response to various antigens and predetermines the body's susceptibility or immunity to diseases, the occurrence of which is mediated by the immune system. Polymorphism is closely associated with ethnic factors, and therefore individuals 
belonging to different ethnic groups differ in allele combinations. responsible for a particular variant of the immune response and, accordingly, for the clinical variant and the outcome of the disease. So. In the population of patients with $\mathrm{H}$. pyori infection in Japan, a relationship between the HLA DRB1 * 0405 and DQB1 * 0401 alleles with gastric ulcer (PUD) and duodenal ulcer (DU) was noted. while in the Finnish, German and Italian populations, no such connection was found. A number of authors have described the relationship between HLA DRB1 * 11 and HLA DRB1 * 04 and the organism's susceptibility to H. pylori ("provocateurs" genes) and the HLA genes DRB1 * 12 and HLA DRB1 * 0301 - with the organism's immunity to H. pyon (genes "Protectors"). Another group of authors does not confirm the existence of such a connection. To date, in the Russian Federation, a few works have been published on the study of the relationship of polymorphism of $\mathrm{HbA}$ genes of class II in populations of children suffering from gastroduodenal pathology associated with $\mathrm{H}$. pyon. Researchers have established a relationship between HLA DR4 (a marker of a risk factor) and the formation of chronic gastroduodenitis in children. In the context of our At the same time, such studies were not carried out in the republic. the tendency to weight gain, rejuvenation and a high frequency of complications dictate the need to study this issue.

There were 115 patients under observation, aged from 3 to 17 years. Of these, 55 patients with duodenal ulcer and stomach ulcer and 60 - with chronic erosive gastroduodenitis

There were 63 boys. 52 girls. The control group included 102 practically healthy children of the same age and sex category. The clinical picture of peptic ulcer manifested itself in the form of the following symptom complexes: abdominal pain ( 96 * o). dyspeptic (100\%). asthenovegetative (94.5\%). which were expressed to varying degrees and were found in different combinations.

\section{CONCLUSIONS}

We investigated the associations between the $\mathrm{HbA}-\mathrm{Er}$ Hoshin variation and the prevalence of H. pyori in a population with an H.py1ori level of $11.2 * *$ in people living in the Bukhara region. It was noted that persons carrying the genotypes $1 X^{\wedge} B 1 * 0401$. have a significantly higher risk of developing $H$. pyori infection compared with lipas with genotypes EX\} B1 0301. Haplotypes $1 X$ ? A1 or OOB1 were not associated with $\mathrm{H}$. pyori infection.

\section{REFERENCES}

1. Baranov A.A. Shcherbakov P.L. Topical issues of pediatric gastroenterology

2. The issue of modern pediatrics 2002. №1.C.12-16

3. Bulatov V.P. Kamalova A.A. Khusnullina G.F. Clinical and endocopic features of peptic ulcer disease in children. Pediatric gastroentology-2005 P.215-216.

4. Zakamerny A.G. Features of the current course of peptic ulcer disease in childhood and approaches to the staged treatment of patients. Therapist. Arch. 1995. No. 2.C23-26

5. Pediatric gastroentology. Ed. A.A. Baranova, E.V. Klimanskaya, G.V. Rimarchuk, M. 2002.

6. Belmer S.V. Duodenal ulcer in children: Abstract of the thesis. ... Dr. med. Sciences. Moscow 1997

7. Maev I.V. Vyuchnova E.S. Diagnostics and treatment of gastric ulcer and duodenal ulcer M.2003

8. Honda S. Fujioka T. Tokieda M. et.al (1998). Development of Helicobacter 
pylori-induced gastric carcinoma in Mongolian gerbils. Cancer Res. 58, 4255-9.

9. Huang YK, Wen GS, Li HL, et al (2005). Possible association between HLA-HRB1 and DQB1 genes frequency and susceptibilityor resistanseto Helicabacter pylori infection in Kunming Yi ethnic group children. Zhong hua Er Ke Za Zhi 137-40.

10. Kaufman JF, Auffray C, Korman AJ, et al (1984). The class II moduceles of the human and murine major histocompatibility complex. Cell. 36,1-13.

11. Klein PD, Graham DY, Gaillour A et al (1991) Water source as risk factor for Helicobacter pylori infection Peruvian children. Gastrointestinal Physiology Working G. Lancet. 22.1503-6.

12. Ko KP, Park SK, Park B, et al (2010). Isoflavones from phytoestrogens and gastric cancer risk: a nested case control study within the Korean Multicenter Cancer Cohort. Cancer Epademiol Biomarkers Prev 19.1292-300.

13. Kusters JG, Van Vliet AH, Kuipers EJ (2006). Pathogenesis v036. Helicobacter pylori infection. Clin Microbiol Rev. 19.44990.

14. Lee JH, Kim N, Chung Jl, et al (2008). Long-trem follow-up of Helicobacter pylori serology after eradication and reinfection rate of $\mathrm{H}$. pylori in South Korea. Helicobacter

15. Kunstmann E., Hardt C., Crabtree J. et al. 2003

16. Brillantino A. et al. Role of tridimensional endoanal ultrasound (3D-EAUS) in the preoperative assessment of perianal sepsis. IntJ Colorectal Dis 2015; 30 (4): 53542.

17. Toyonaga T. et al. Comparison of accuracy of physical examination and endoanal ultrasonography for preoperative assessment in patients with acute and chronic analfistula. Tech Coloproctol 2008; 12 (3): 217-23.

18. Wedemeyer J. et al. Transcutaneous perianal sorography: a sensitive method for the detection of perianal inflammatory lesions in Crohn's diseave. World J Gastroenterol 2004; 10 (19): 2859-63.

19. Youssef A.T. Imaging Classification of Perianal Fistula Using the Ultrasound. J Gastroenterol Hepatol Res 2015; 4 (6): 1653-9.

20. Garcia-Granero A. et al. Management of cryptoglandular supralevator abscesses in the magnetic resonance imaging era: acase series. Int J colorectal Dis 2014; 29 (12): $1557-64$.

21. Siddiqui M.R.S. et al. A diagnostic accuracy meta-analysis of endoanal ultrasound and MRI for perianal fistula assessment. Dis Colon Rectum 2012; 55 (5): 576-85.

22. Jordan J. et al. Risk factors for recurrence and incontinence after anal fistula surgry. Colorectal Dis 2010; 12 (3): 254-60.

23. Arroyo A. et al. Fistulotomy and sphincter reconstruction in the treatment of coplex fidtula-in-ano: long-term clinical and manometric results. Ann Surg 2012; 255 (5): 935-9.

24. Toyonaga $T$. et al. Factors affecting continence after fistulotomy for instersphincteric fistula -in-ano. Int J Colorectal Dis 2007; 22 (9): 1071-5.

25. Visscher A.P. et al. Long-term Follow-up After Surgery for Simple and Complex Cryptoglandular Fistulas: Fecal Incontinence and Impact on Quality of Life. Dis Colon Rectum 2015; 58 (5): 533-9.

26. Roig.J.V. et al. Changes in anorectal morphologic and functional parameters after fistula-in-ano surgery. Dis Colon Rectum 2009; 52 (8): 1462-9.

27. Vial $M$. et al. Faecal incontinence after seton treatment for anal fistulae with and 
without surgical division of internal anal sphincter: a systematic review. Colorectal Dis 2010; 12 (3): 172-8.

28. Chand S.C., Lin J.K. Change in anal continence after surgery for intersphincteral anal fistula: a functional and manometric study. Int J Colorectal Dis 2003; 18 (2): 111-5.

29. Gabriel W.B. The treatment of pruritus ani and anal fissure. $\mathrm{Br} M$ ed J 1930; 2 (3634): 311.

30. Bernard D., Tasse D., Morgan S. High intermuscular anal abscess and fistula: analysis of 25 cases. Can J Surg 1983 Mar .; 26 (2): 136-9.

31. Gottgens K.W.A. et al. Long-term outcome of low perianal fitulas treated by fistulomoty a multicenter study. Int J Colorectal Dis 2015; 30 (2): 213-9.

32. Hirschburger $M$. et al. Fistulectomy with primary sphincter reconstruction in the treatment of high transsphincteric anal fistulas. Int J Colorectal Dis 2014; 29 (2): 247-52.

33. Elting A.W.X. The treatment of fistula in ano: with especial reference to the whitehead operation. Ann Surg 1912; 56 (5): 744-52.

34. Ramirez A., Virgilio A., Fistulas anorrectales: tratamiento quirurgico con el metodo de Robles y Picot: experiencia personal. Prensa Med Argent 1985; 72 (15): 511-4.

35. Kirschner M. Die Eingriffe am Mastdarm. Die Eingriffe in der Bauchhohle. - BerlinHeidelberg: Springer-Verlag 1951.551 p. 